\title{
KEPUASAN PASIEN RAWAT INAP DAN RAWAT JALAN TERHADAP PELAYANAN GIZI PASIEN DIET DIABETES MELLITUS
}

\author{
Silvia Anggrianni, Iwan Setiadi Adji, Amin Mustofa, M. Farid Wajdi \\ Program Studi Magister Manajemen, Sekolah Pascasarjana \\ Universitas Muhammadiyah Surakarta \\ Jl. Ahmad Yani Tromol Pos 1, Pabelan Surakarta 57102 \\ Email: anggriavii@gmail.com
}

\begin{abstract}
This research aims to identify and evaluate: 1) the performance of health workforce to satisfaction of patient with diabetes mellitus. 2) The obedience of eating schedule to satisfaction of patient with diabetes mellitus. 3) The obedience of food type to satisfaction of patient with diabetes mellitus. The data of this research is the premier data which was obtained from the answers of 100 respondents with accidental sampling method. This research is using multiple linear regression analysis. The test result concluded that all variables instrument are valid and reliable as a data collecting tool. In the data analysis shows that: 1) There is effect of the performance of health workforce to satisfaction of patient with diabetes mellitus. 2) There is not effect of the obedience of eating schedule to satisfaction of patient with diabetes mellitus. 3) There is not effect of the obedience of type food to satisfaction of patient with diabetes mellitus.
\end{abstract}

Key Word: Performance of health workforce, schedule, type, patient satisfaction, diabetes mellitus.

\begin{abstract}
Abstrak
Penelitian ini bertujuan untuk mengetahui dan mengevaluasi pengaruh: 1) kinerja tenaga kesehatan terhadap kepuasan pasien diabetes mellitus. 2) kepatuhan ketepatan jadwal makan terhadap kepuasan pasien diabetes mellitus. 3) kepatuhan jenis makanan terhadap kepuasan pasien diabetes mellitus. Data yang digunakan adalah data primer yang diperoleh dari jawaban 100 orang responden dengan metode accidental sampling. Alat analisis data menggunakan analisis regresi linier berganda. Hasil pengujian instrumen menyimpulkan bahwa semua variabel valid dan reliabel sebagai alat pengumpul data. Dari hasil analisis data didapatkan bahwa: 1) Ada pengaruh kinerja tenaga kesehatan terhadap kepuasan pasien diabetes mellitus. 2) Tidak ada pengaruh kepatuhan ketepatan jadwal makan terhadap kepuasan pasien diabetes mellitus. 3) Tidak ada pengaruh kepatuhan jenis makanan terhadap kepuasan pasien diabetes mellitus.
\end{abstract}

Kata Kunci: Kinerja tenaga kesehatan, jadwal, jenis, kepuasan pasien, diabetes mellitus.

\section{Pendahuluan}

Rumah sakit merupakan sarana kesehatan yang memb erikan jasa kesehatan dalam upaya meningkatan derajat kesehatan. Sejalan dengan pendapat Herlambang (2016 : 73) bahwa, mutu pelayanan kesehatan adalah 
pelayanan yang menggunakan sumber daya yang tersedia di rumah sakit sesuai kode etik yang telah ditetapkan secara efesien dan efektif dalam upaya pemenuhan derajat kesehatan sehingga pasien merasa aman dan puas.

Kepuasan pasien tidak hanya dari meningkatkan fasilitas lingkungan fisik, tetapi adanya upaya untuk memberikan kepuasan kepada pasien terutama pada proses interaksi antara pasien dengan petugas dalam memberikan pelayanan kesehatan. Seperti yang dinyatakan Pohan (2013 : 156) bahwa, kepuasan pasien adalah harapan pasien yang timbul atas tindakan tenaga kesehatan sebagai akibat dari kinerja layanan kesehatan selama proses berinteraksi dalam upaya memberikan pelayanan.

Rumah sakit dituntut agar selalu menjaga kepercayaan konsumen dengan cara meningkatkan pelayanan agar kepuasan pasien terus meningkat. Menurut Depkes RI (2005 : 19) bahwa, pelayanan gizi rawat inap dan rawat jalan adalah serangkaian kegiatan yang dilakukan secara berkesinambungan untuk memenuhi kebutuhan gizi pasien dimulai dari perencanaan hingga evaluasi diet pasien. Adapun kegiatan pelayanan gizi di rumah sakit adalah pelayanan gizi yang disesuaikan dengan keadaan pasien maupun keadaan klinisnya, serta status gizi, dan metabolisme tubuh pasien tersebut. (Depkes RI, $2005: 7$ ). Pelayanan gizi rawat inap dapat dilakukan dengan adanya penyelenggaraan makanan di rumah sakit, sedangkan pelayanan gizi rawat jalan dapat dilakukan dengan asuhan gizi seperti konseling gizi kepada pasien.

Diabetes Mellitus adalah peningkatan kadar glukosa darah yang timbul karena kekurangan hormon insulin.Tujuan diet penyakit diabetes mellitus adalah upaya untuk memperbaiki pola makan serta gaya hidup yang sehat dengan berolahraga agar dapat mengontrol metabolik yang lebih baik. (Almatsier, 2004 : 137). Pada kasus pasien dengan diet diabetes mellitus sangat erat kaitannya dengan kepatuhan diet diabetes itu sendiri. Perlu adanya penyelenggaraan makanan yang tepat sehingga dapat melakukan penanganan yang lebih baik, karena dalam pemberian makanan harus sesuai dengan kebutuhan zat gizi yang diperlukan pasien agar tidak terjadi komplikasi. Seperti dinyatakan oleh Risnasari (2010:18) bahwa, di Puskesmas Pesantren II Kota Kediri didapatkan dari 57 responden ada 33 orang mengalami komplikasi (57,89\%). Sejalan dengan pendapat Mansjoer dkk (2001) dalam Risnasari (2010 : 19) mengemukakan bahwa, tingkat kepatuhan pasien dalam menaati diet mempengaruhi terhadap munculnya komplikasi.

Prayugo dkk (2012: 78) menyatakan bahwa, "Melakukan diet tepat jadwal makan di instalasi rawat jalan rumah sakit Baptis Kediri lebih sedikit (26,7\%) dibandingkan pasien yang tidak diet tepat jadwal (73,3\%)". Faktor yang mempengaruhi pasien tidak tepat jadwal karena pekerjaan atau aktivitas yang dilakukan sehingga sulit untuk mengikuti sesuai jadwal yang sudah ditentukan.

Prayugo dkk (2012) mengemukakan bahwa, "Pasien yang tidak melakukan diet tepat jenis dipengaruhi oleh faktor pengetahuan dan kesadaran hidup sehat". Mengingat pentingnya pola pemberian diet pada pasien diabetes mellitus di rumah sakit, maka peneliti tertarik untuk meneliti tentang evaluasi kepuasaan pasien rawat inap dan rawat jalan terhadap pelayanan gizi rumah sakit yang meliputi kinerja tenaga kesehatan, kepatuhan ketepatan jadwal makan dan kepatuhan jenis makanan pasien dengan diet diabetes mellitus. Sehingga dapat menekan serendah mungkin untuk terjadinya komplikasi pada pasien diabetes mellitus, serta merupakan salah satu indikator penting untuk menilai tingkat keberhasilan pelayanan gizi pasien rawat inap dan rawat jalan. Selain itu juga penulis berharap, hasil penelitian ini nantinya akan sangat bermanfaat sebagai bahan evaluasi di rumah sakit.

\section{Tinjauan Pustaka}

Menurut UU No. 44 tahun (2009) dalam Herlambang (2016) bahwa, rumah 
sakit adalah institusi pelaynan kesehatan yang menyelenggarakan pelayanan kesehatan perorangan secara paripurna yang menyediakan pelayanan rawat inap dan rawat jalan serta rawat darurat. Menurut Herlambang (2016: 34) rumah sakit umum mempunyai misi memberikan pelayanan kesehtaan yang bermutu dan terjangkau oleh masyarakat dalam rangka meningkatkan derajat kesehatan masyarakat.

Standar pelayanan rumah sakit diatur dalam peraturan Menteri Kesehatan Nomer 129/Menkes/SK/II/2008 dalam Herlambang (2016: 41) meliputi:

1. Pelayanan gawat darurat, pelayanan rawat jalan dan rawat inap

2. Pelayanan bedah, persalinan dan perinatology

3. Pelayanan itensif, radiologi dan laboratorium patologi klinik

4. Pelayanan rehabilitasi medik, farmasi, dan pelayanan gizi

5. Pelayanan transfusi darah, pelaynan keluarga miskin dan rekam medis

6. Pelayanan administrasi manjemen, ambulans, dan pemulasaran jenazah

7. Pelayanan laundry, pengolahan limbah dan pemeliharaan sarana rumah sakit.

\section{Kepuasan Pasien}

Kepuasan pasien adalah harapan pasien yang ditimbul sebagai akibat dari dalam upaya melakukan peningkatan kualitas mutu pelayanan kesehatan, perlu adanya pengukuran tingkat dari kepuasan pasien itu sendiri agar dapat mengetahui dimensidimensi mutu pelayanan sudah sejauh mana pemenuhan harapan pasien sudah diselenggarakan. (Pohan, 2007:156). Menurut Pohan (2013:145) bahwa, dalam konsep kepuasan penyelenggaraan layanan kesehatan dan kepuasan pasien meliputi:

1. Konsisten pada standarisasi kompetensi teknik memberi layanan kesehatan.

2. Pemenuhan standar meliputi petugas, kebijaksanaan, obat, lingkungan gedung serta peralatannya
3. Terjalinnya sikap saling menghargai antar manusia dalam kenyamanan, kebersihan

4. Memberi kemudahan pasien untuk fokus mengatur sistem layanan kesehatan

Kepuasan pasien akan timbul apabila harapan yang diperoleh sama atau melebihi terhadap kinerja layanan kesehatan sedangkan ketidakpuasan pasien akan timbul apabila harapan yang diperoleh tidak sesuai. (Pohan, 2007 : 156)

\section{Pelayanan Gizi Rumah Sakit}

MenurutAzwar(1996)dalamHerlambang (2016 : 72) bahwa, mutu pelayanan kesehatan adalah tingkat kepuasan setiap pemakai jasa dalam pelayanan kesehatan sesuai dengan kode etik profesi. Menurut Departemen Kesehatan RI (2005 : 7) bahwa, pelayanan gizi rumah sakit adalah suatu tindakan layanan gizi yang telah disesuaikan dengan metabolisme tubuh pasien, serta keadaan klinis maupun status gizi pasien. Salah satu penunjang utama dalam upaya penyembuhan pasien adanya tindakan terapi gizi yang tentunya harus diperhatikan agar dalam melaksanakan fungsi metabolisme tidak melebihi kemampuan organ.

Indikator Keberhasilan Pelayanan Gizi Rumah Sakit Menurut Departemen Kesehatan RI (2005: 90) meliputi terwujudnya pemenuhan baik kebutuhan gizi, serta evaluasi sesuai dengan standar diet yang ditinjau dari keadaan pasien, terselenggaranya diagnosis dan pengkajian yang tepat berdasakan gejala klinis, biokimia, dan data antropometri pasien, dan terselenggaranya penyuluhan dan konseling tentang pentingnya diet pada pasien dan keluarganya serta terwujudnya bentuk pembelian bahan makanan, jumlah pemberian serta cara makannya, pemilihan pengelolahannya.

\section{Kinerja Tenaga Kesehatan}

Menurut Undang Undang Nomor 36 Tahun 2014 dalam Kemenkes RI (2015: 47) bahwa, tenaga kesehatan adalah orang yang bekerja dalam bidang kesehatan sesuai 
dengan keterampilan dan pengertahuan dalam melakukan upaya kesehatan. Tenaga kesehatan itu sendiri dapat dikelompokkan menjadi tenaga medis, perawat, bidan, kesehatan masyarakat, psikolog, kesehtaan lingkungan, farmasi, tenaga gizi, tenaga terapi fisik dan medis, serta tenaga biomedika dan lainnya.

Menurut UU No. 44 Tahun 2009 tentang rumah sakit tenaga kesehatan merupakan sumber daya manusia dari tenaga tetap yang tersedia dirumah sakit. Tenaga tetap sumber daya rumah sakit meliputi: tenaga medis dokter \& penunjang medis, tenaga kefarmasian, perawat, manajemen rumah sakit dan tenaga non kesehatan.

Sedangkan menurut Notoatmodjo (2007) dalam Sudian (2011 : 8) bahwa, sikap adalah respon seseorang pada objek manifestasi sikap tidak dapat dilihat langsung, hanya dapat dilihat dari sikap tertutup. Secara nyata sikap dalam keseharian merupakan reaksi dari stimulus emosional tertentu. Sikap adalah kesedian tindakan.

\section{Diabetes Mellitus}

Diabetes mellitus adalah gejala yang timbul karena mengalami peningkatan kadar gula pada seseorang . (Almatsier, 2004: 137). Menurut Almatsier (2004: 137), tujuan diet penyakit diabetes mellitus adalah mengontrol kebiasaan makan dan pola hidup pasien dalam upaya membantu mendapatkan kontrol metabolik yang lebih baik, dengan cara: menyeimbangkan asupan makanan pasien dengan memberi cukup energi untuk mempertahankan kadar gula darah sehingga dapat mendekati normal, meningkatkan derajat kesehatan secara menyeluruh untuk menghindari komplikasi akut menggunakan insulin, seperti hipoglikemia..

\section{Ketepatan Jadwal Makan}

Menurut Tjokroprawiro (2006) dalam Prayugo dkk (2012 :72) bahwa, jadwal makan penderita diabetes mellitus harus diikuti sesuai intervalnya yaitu tiap 3 jam. Pada dasarnya diet diabetes mellitus diberikan dengan cara
3 kali makanan utama dan tiga kali makanan selingan dengan jarak antara 3 jam.

Menurut Depkes RI (2005: 25) menyatakan bahwa, penyelenggaraan makanan rumah sakit adalah serangkaian kegiatan pendistribusian makanan yang dimulai dari perencanaan menu makanan kepada konsumen, sehingga secara optimal dapat memberikan makanan secara tepat dalam upaya pencapaian status kesehatan. Depkes RI (2007 :10) menyatakan bahwa, peraturan pemberian makanan rumah sakit adalah pedoman pelayanan gizi pada pasien sesuai acuan yang telah ditetapkan oleh pimpinan rumah sakit berdasarkan standar makanan, pola makan, nilai gizi serta jenisnya. Pengaturan jadwal bagi penderita diabetes biasanya adalah 6 kali makan. 3 kali makan utama dan 3 kali selingan dengan interval 3 jam.

\section{Jenis Makanan Diabetes Mellitus}

Jenis makanan yang dianjurkan dan yang tidak dianjurkan oleh pasien dengan diet diabetes mellitus. Menurut PERKENI (2011: 15) bahwa, terapi nutrisi medis merupakan bagian dari penatalaksanaan diabetes mellitus secara total. Kunci keberhasilan terapi nutrisi medis adalah keterlibatan secara menyeluruh dari anggota tim ( dokter, ahli gizi, petugas kesehatan yang lain serta pasien dan keluarga).

Menurut Almatsier (2004) bahwa, bahan makanan yang tidak dianjurkan penderita diabetes, atau dihindari untuk diet diabetes mellitus adalah Mengandung banyak gula sederhana, seperti: Gula pasir, gula jawa, kuekue manis, dodol, cake, dan tar. Sirop, jeli, buah-buahan yang diawetkan dengan gula, susu kental manis, minuman botol ringan, dan es krim.

\section{Metodologi Penelitian}

\section{Jenis Penelitian}

Jenis penelitian yang digunakan pada penelitian ini adalah metode penelitian survei deskriptif dengan cara pendekatan kuantitatif. Seperti dinyatakan oleh Notoatmodjo (2010: 36) bahwa, penelitian survei deskriptif 
adalah suatu penelitian yang dilakukan untuk mendeskripsikan atau menggambarkan masalah kesehatan serta yang terkait dengan kesehatan sekelompok orang.

\section{Lokasi Penelitian}

Lokasi penelitian dilakukan di ruang rawat inap kelas II, III dan di ruang rawat jalan poliklinik di RSU PKU Muhammadiyah Bantul. Waktu penelitian dilakukan selama 1 bulan.

\section{Populasi dan Sampel}

Pengambilan sampel pada penelitian ini adalah semua pasien diabetes mellitus yang menjalani rawat inap dan rawat jalan di RSU PKU Muhammadiyah Bantul. Jumlah sampel sebanyak 100 responden. Teknik penelitian ini dipilih secara accidental sampling.

\section{Definisi Operasional Variabel}

a. Kepuasan pasien (Y)

Kepuasaan pasien adalah tingkat perasaan pasien yang timbul sebagai akibat dari kinerja pelayanan kesehatan yang diperolehnya setelah pasien membandingkannya dengan apa yang diharapkannya (Pohan, 2007: 156). Indikator pada kepuasan pasien ini mengacu pada kuesioner dari Kusumaningrum (2013) meliputi: pertama kepuasan pada metode kerja pelayanan, kedua kepuasan pelayanan menyeluruh, ketiga kepuasan kualitas layanan petugas, keempat kepuasaan waktu pemeriksaan dan hasil yang diperoleh, dan kepuasan perhatian yang bersifat tulus dari tenaga kesehatan.

b. Kinerja Tenaga Kesehatan $\left(\mathrm{X}_{1}\right)$

Kinerja adalah hasil kerja secara kualitas dan kuantitas yang dicapai oleh seseorang petugas dalam melaksanakan tugasnya sesuai dengan tanggung jawab yang diberikan kepadanya. ( Mangkunegara, 2000 dalam Wikipedia). Indikator pada kinerja tenaga kesehatan ini mengacu pada kuesioner Kusumaningrum (2013) meliputi: pertama kinerja secara keseluruhan staf sangat kompeten, kedua kinerja karyawan menghargai hak pasien, ketiga pasien merasa nyaman berinteraksi, keempat pasien merasa dilayani dengan baik, dan kelima penanganan yang baik atas keluhan pasien.

c. Ketepatan Jadwal Makan $\left(\mathrm{X}_{2}\right)$

Jadwal dalam pedoman $3 \mathrm{~J}$ adalah ketepatan jadwal makan pasien diet diabetes mellitus dengan mengikuti interval waktu yaitu 3 jam. Tjokroprawiro (2006) dalam Prayugo dkk (2012: 79-80). Indikator pada ketepatan jadwal makan ini mengacu pada kuesioner dari Fatima (2014) meliputi: pertama pemberian makanan utama sebanyak 3 kali, kedua pemberian makanan selingan sebanyak 3 kali, ketiga selang waktu makan selama 3 jam, keempat pemberian jam makan makanan utama pasien, dan kelima pemberian jam makan makanan selingan pasien.

d. Jenis Makanan Diabetes Mellitus $\left(\mathrm{X}_{3}\right)$

Jenis dalam pedoman $3 \mathrm{~J}$ adalah kesesuaian jenis bahan makanan yang dianjurkan dan tidak dianjurkan dalam menu diet diabetes mellitus. Tjokroprawiro (2006) dalam Prayugo dkk (2012: 7980). Indikator pada jenis makanan diet diabetes mellitus ini mengacu pada kuesioner dari Fatima (2014) meliputi: prinsip diet diabetes mellitus adalah tepat jenis, kedua makanan yang sebaiknya dimasak menggunakan sedikit minyak, ketiga contoh makanan yang dimakan dalam sehari, keempat makanan yang tidak dianjurkan penderita diabetes.

\section{Data dan Teknik Pengumpulan Data}

a. Data

Data primer yang diperlukan dalam penelitian ini adalah karakteristik dan responden terhadap variabel kepuasaan pasien, kinerja tenaga kesehatan, kepatuhan ketepatan jadwal makan dan kepatuhan jenis makanan diet diabetes mellitus. 


\section{b. Teknik Pengumpulan Data}

Dalam penelitian ini kuesioner tertutup, karena pertanyaan yang disediakan sudah mempunyai alternatif jawaban yang bisa dipilih oleh responde.

\section{Metode Analisis Data}

\section{a. Analisis Multivariate}

Menurut Notoatmodjo (2010 : 184) bahwa, analisis multivariate ini digunakan untuk mengetahui hubungan lebih dari satu variabel indenpenden dengan satu variabel dependen. Uji statistik yang digunakan biasanya regresi berganda,

Selain itu juga akan dianalisis menggunakan analisis deskriptif yang bertujuan untuk membuat gambaran atau deskripsi tentang suatu keadaan secara objektif. (Notoatmojo, 2002: 188).

b. Uji Asusmsi Klasik

Uji normalitas bertujuan untuk menguji model regresi pada residual mempunyai distribusi yang normal. (Ghozali, 2013: 160)

\section{c. Pengujian Hipotesis}

Regresi linier berganda digunakan apabila variabel bebas lebih dari satu dan untuk mengukur pengaruh variabel bebas terhadap variabel terikat. (Notoatmodjo,
2010: 184). Rumus Regresi Linier Berganda : $\mathrm{Y}=\mathrm{a}+\mathrm{b}_{1} \mathrm{X}_{1}+\mathrm{b}_{2} \mathrm{X}_{2}+\mathrm{b}_{3} \mathrm{X}_{3}+\mathrm{e}$

Uji $t$ dapat digunakan untuk mengukur pengaruh secara signifikan antara variabel independen dan variabel dependen. Apabila $t_{\text {hitung }}$ lebih besar dari pada $t_{\text {tabel }}$ berarti ada pengaruh yang signifikan antara variabel $\mathrm{X}$ dengan variabel Y secara parsial.

Pengujian $\mathrm{F}$ hitung digunakan untuk mengetahui kualitas variabel independen secara simultan dapat mempengaruhi variabel dependen. (Ghozali, 2013:177).

Uji koefisien determinasi digunakan untuk mengetahui seberapa besar varian dari variabel dependen dapat dijelaskan oleh variabilitas variabel independen. (Ghozali, 2013:177).

\section{Hasil Dan Pembahasan}

\section{Deskripsi Data}

Analisis deskriptif pada penelitian ini bertujuan untuk menggambarkan dan mendeskripsikan secara ringkas informasi dari data responden mengenai variabel kinerja tenaga kesehatan, kepatuhan ketepatan jadwal makan dan kepatuhan jenis makanan diabetes mellitus.

Tabel 1

Hasil Statistik Deskriptif

\begin{tabular}{lccccc}
\hline \multicolumn{1}{c}{ Variabel } & N & Min & Maks & Mean & Std. Deviasi \\
\hline Kinerja Tenaga Kesehatan $\left(\mathrm{X}_{1}\right)$ & 100 & 18.00 & 25.00 & 22.3500 & 1.94040 \\
Ketepatan Jadwal $\left(\mathrm{X}_{2}\right)$ & 100 & 15.00 & 25.00 & 18.8400 & 2.33861 \\
Jenis Makanan $\left(\mathrm{X}_{3}\right)$ & 100 & 12.00 & 20.00 & 16.4200 & 2.16576 \\
Kepuasaan Pasien $(\mathrm{Y})$ & 100 & 19.00 & 25.00 & 22.0300 & 1.87732 \\
\hline
\end{tabular}

Sumber: Data primer diolah, 2016

Hasil dari uji deskriptif data dapat dilihat pada $\mathrm{X}_{1}$ nilai minimal sebesar 18.00 sedangkan untuk nilai maksimal 25.00, pada $\mathrm{X}_{2}$ nilai minimal 15.00 sedangkan nilai maksimal 25.00 , pada nilai $\mathrm{X}_{3}$ pada nilai minimal sebesar 12.00 sedangkan nilai maksimal sebesar 20.00 , serta pada $Y$ nilai minimal sebesar 19.00 sedangkan nilai maksimal sebesar 25.00.

\section{Hasil Uji Analisis Regresi Linier Berganda}

Untuk menganalisis pengaruh variabel kinerja tenaga kesehatan $\left(\mathrm{X}_{1}\right)$, kepatuhan ketepatan jadwal makan $\left(\mathrm{X}_{2}\right)$, dan kepatuhan jenis makanan diabetes mellitus $\left(\mathrm{X}_{3}\right)$ digunakan metode statistik regresi linier berganda dengan taraf signifikan $\alpha=0,05$ artinya derajat kesalahan sebesar 5\%. 
Tabel 2

\begin{tabular}{lcccc}
\multicolumn{4}{c}{ Hasil Analisis Regresi Linier Berganda } \\
\hline \multicolumn{1}{c}{ Variabel } & $\begin{array}{c}\text { Unstandardized } \\
\text { Coefficients }\end{array}$ & T & Sig & Keterangan \\
\cline { 2 - 4 } & 13.476 & 6.012 & 0.000 & \\
\cline { 2 - 3 }$($ Constant $)$ & 0.303 & 3.066 & 0.003 & Signifikan \\
$\begin{array}{l}\text { Kinerja tenaga kesehatan } \\
\left(\mathrm{X}_{1}\right)\end{array}$ & 0.158 & 1.741 & 0.085 & Tidak signifikan \\
$\begin{array}{l}\text { Ketepatan jadwal }\left(\mathrm{X}_{2}\right) \\
\text { Jenis makanan DM }\left(\mathrm{X}_{3}\right)\end{array}$ & -0.073 & -.796 & 0.428 & Tidak signifikan \\
\hline
\end{tabular}

Sumber: Data primer diolah, 2016

Dari hasil analisis regresi berganda di atas, dapat diperoleh persamaan sebagai berikut :

$\mathrm{Y}=13.476+0,303 \mathrm{X}_{1}+0,158 \mathrm{X}_{2}-0,073 \mathrm{X}_{3}$ $+\mathrm{e}$

Berdasarkan persamaan regresi linier tersebut di atas dapat disimpulkan sebagai berikut :

a. Nilai koefisien regresi untuk variabel kinerja tenaga kesehatan $\left(\mathrm{X}_{1}\right)$ sebesar positif 0,303 berarti bahwa setiap kenaikan variabel kinerja tenaga kesehatan $\left(\mathrm{X}_{1}\right)$ akan menaikkan kepuasan pasien.

b. Nilai koefisien regresi untuk variabel ketepatan jadwal makan $\left(\mathrm{X}_{2}\right)$ sebesar positif 0,158 berati bahwa setiap kenaikan variabel ketepatan jadwal makan $\left(\mathrm{X}_{2}\right)$ akan menaikkan kepuasan pasien.

c. Nilai koefisien regresi untuk variabel jenis makanan diabetes mellitus $\left(\mathrm{X}_{3}\right)$ sebesar negatif 0,073 berarti bahwa setiap kenaikan jenis makanan diabetes mellitus $\left(\mathrm{X}_{3}\right)$ akan menurunkan kepuasan pasien

\section{Uji t (Uji Parsial)}

Nilai t menunjukkan pengujian variabelvariabel independen secara parsial, yang dilakukan untuk melihat apakah variabel independen secara parsial mempunya pengaruh signifikan terhadap variabel dependen.

Tabel 3

\begin{tabular}{ccccc}
\multicolumn{1}{c}{ Hasil Uji t } & & \\
\hline Variabel & $\mathbf{t}_{\text {hitung }}$ & $\mathbf{t}_{\text {tabel }}$ & $\mathbf{p}_{\text {value }}$ & Keterangan \\
\hline Kinerja tenaga kesehatan $\left(\mathrm{X}_{1}\right)$ & 3.066 & 1,987 & 0.003 & Signifikan \\
Ketepatan jadwal $\left(\mathrm{X}_{2}\right)$ & 1.741 & 1,987 & 0.085 & Tidak Signifikan \\
Jenis makanan DM $\left(\mathrm{X}_{3}\right)$ & -0.796 & 1,987 & 0.428 & Tidak Signifikan \\
\hline
\end{tabular}

Sumber: Data primer diolah, 2016

Berdasarkan hasil analisis uji t seperti pada Tabel4.18 diatas dapatdiketahuibahwa masingmasing variabel independen (kinerja tenaga kesehatan) mempunyai nilai $\mathrm{t}_{\text {hitung }}$ lebih besar dari $t_{\text {tabel }}(1,987)$, sehingga dapat disimpulkan bahwa kinerja tenaga kesehatan secara parsial mempunyai pengaruh yang signifikan terhadap kepuasaan pasien. Sedangkan pada variabel kepatuhan ketepatan jadwal makan dan kepatuhan jenis makanan diabetes mellitus secara parsial tidak mempunyai pengaruh yang signifikan terhadap kepuasan pasien di RSU PKU Muhammadiyah Bantul Yogyakarta.

\section{Uji F (Uji Pengaruh Simultan)}

Pengujian ini dimaksudkan untuk mengetahui kualitas variabel independen secara simultan dapat mempengaruhi variabel dependen. (Ghozali, 2013:177). Uji kelayakan model menggunakan uji $\mathrm{F}$. 
Tabel. 4

Hasil Uji F

\begin{tabular}{cccc}
\hline & F & Signifikan & Kesimpulan \\
\hline Model & 6,480 & 0,000 & Model Fit/tepat \\
\hline
\end{tabular}

Sumber: Data primer diolah, 2016

Berdasarkan uji $\mathrm{F}$ pada tabel 4.19 terlihat bahwa nilai $\mathrm{F}_{\text {hitung }}$ sebesar 6,480 lebih besar dari $\mathrm{F}_{\text {tabel }}(2,75)$ maka dapat disimpulkan bahwa model yang digunakan dalam penelitian tepat atau fit atau terdapat pengaruh antara kinerja tenaga kesehatan, kepatuhan ketepatan jadwal makan dan kepatuhan jenis makanan diabetes mellitus secara simultan terhadap kepuasan pasien diabetes mellitus di ruang rawat inap dan rawat jalan RSU PKU Muhammadiyah Bantul Yogyakarta.

\section{Uji Hasil Analisis Koefisien Determinasi $\left(\mathbf{R}^{2}\right)$}

Analisis koefisien determinasi digunakan untuk mengetahui seberapa besar varian dari variabel dependen dapat dijelaskan oleh variabilitas variabel independen. (Ghozali, 2013:177).

Tabel 5

Hasil Uji Analisis Koefisien ( $\left.\mathbf{R}^{2}\right)$

\begin{tabular}{ccccc}
\hline Model & R & R Square & Adjusted R Square & $\begin{array}{c}\text { Std. Error of the } \\
\text { Estimate }\end{array}$ \\
\hline 1 & $0.410^{\mathrm{a}}$ & 0.168 & 0.142 & 1.73851 \\
\hline \multicolumn{5}{c}{ Sumber: Data primer diolah, 2016 } \\
\hline
\end{tabular}

Berdasarkan tabel 4.20 di atas dilihat besar nilai $R$ Square sebesar 0,168 (16,8\%). Dengan demikian dapat dikatakan bahwa besarnya pengaruh variabel kinerja tenaga kesehatan, kepatuhan ketepatan jadwal makan dan kepatuhan jenis makanan diabetes mellitus terhadap kepuasan pasien adalah $16,8 \%$ sedangkan sisanya $(83,2 \%)$ dipengaruhi oleh variabel lain di luar penelitian.

\section{Pembahasan}

1. Evaluasi kepuasan pasien terhadap kinerja tenaga kesehatan di RSU PKU Muhammadiyah Bantul Yogyakarta.

Menurut Notoatmodjo (2007) dalam Sudian (2011 : 8), sikap adalah reaksi atau respon yang masih tertutup dari seseorang terhadap suatu stimulus atau obyek. Manifestasi sikap tidak dapat langsung dilihat, tetapi hanya dapat ditafsirkan terlebih dahulu dari perilaku. Hasil penelitian di RSU PKU Muhammadiyah Bantul ini menunjukkan, bahwa kinerja tenaga kesehatan secara parsial mempunyai pengaruh yang signifikan terhadap kepuasaan pasien. Hal ini terbukti dari nilai $t_{\text {hitung }}$ (3.066) lebih besar dari $t_{\text {tabel }}$ $(1,987)$. Hasil penelitian ini mendukung hasil penelitian yang pernah dilakukan oleh Sudian (2011: 7) menunjukkan bahwa sebanyak $80 \%$ responden merasa puas terhadap sikap petugas yang positif.

Hasil penelitian ini mendukung hasil penelitian yang pernah dilakukan oleh Wike (2009) menyimpulkan bahwa ada pengaruh antara sikap petugas dengan pasien di RSUD Tugurejo Semarang. Dalam penelitian ini responden perempuan maupun laki- laki, yang mayoritas responden berusia $>50$ tahun serta pendidikan dan pekerjaan relatif rendah tetap diperlakukan sama oleh petugas kesehatan. Ketika responden membutuhkan layanan, tenaga kesehatan dengan sigap untuk melayani responden dengan baik dan ramah, karena hampir semua responden maupun keluarga responden sudah mengetahui bahwa sudah ada layanan untuk responden maupun keluarga responden untuk dapat mengajukan complain atau mengkritik secara langsung untuk layanan rumah sakit bila dianggap responden buruk. 
Sehingga mayoritas dari responden yang diteliti sudah merasa ditangani dengan baik dan benar mulai dari pertama datang hingga masuk di ruang rawat inap, begitupun pada pasien diabetes rawat jalan merasa dilayani dengan baik sesuai prosedur. Baik responden yang menggunakan biaya sendiri maupun responden yang menggunakan BPJS maupun jaminan lainnya merasa puas karena tidak merasa dipersulit oleh pihak rumah sakit. Sehingga dapat dikatakan bahwa hipotesis pertama yang diajukan terbukti kebenarannya. Semakin baik kinerja tenaga kesehatan dalam memberikan layanan berarti semakin meningkat juga kepuasan responden. Sejalan dengan pendapat Larrabee (2004) dalam Senarath, et al. (2013:11) menyatakan bahwa, interaksi dengan pasien dianggap sebagai penentu utama kepuasan pasien

\section{Evaluasi kepuasan pasien terhadap kepatuhan ketepatan jadwal makan di RSU PKU Muhammadiyah Bantul} Yogyakarta

Tepat jadwal makan merupakan salah satu prinsip diet diabetes mellitus. Menurut Tjokroprawiro (2006) dalam Prayugo dkk (2012: 79-80) menyatakan bahwa, jadwal diet yang diberikan harus sesuai dengan intervalnya dengan dibagi menjadi 6 waktu. Hasil penelitian di RSU PKU Muhammadiyah Bantul ini menunjukkan, bahwa kepatuhan ketepatan jadwal makan secara parsial tidak mempunyai pengaruh yang signifikan terhadap kepuasaan pasien. Hal ini terbukti dari nilai $t_{\text {hitung }}(1.741)$ lebih kecil dari $t_{\text {tabel }}$ $(1,987)$.

Hasil penelitian ini mendukung hasil penelitian Prayugo dkk (2012) menyatakan bahwa, pasien yang melakukan diet tepat jadwal lebih sedikit dibandingkan pasien yang tidak tepat jadwal makan. Hal tersebut bisa disebabkan karena responden yang menilai bahwa kualitas interaksinya baik dan memuaskan dengan kinerja tenaga kesehatan namun belum semua responden bisa mengatur jadwal makan dengan baik dan benar sesuai prinsip diet diabetes mellitus. Sehingga dapat dikatakan bahwa hipotesis kedua yang diajukan belum terbukti kebenarannya karena dapat diketahui bahwa tidak ada pengaruh antara variabel kepatuhan ketepatan jadwal makan dengan kepuasan responden. Kepuasan responden hanya dipengaruhi oleh bagaimana sikap dan kinerja tenaga kesehatan. Bagaimana tenaga kesehatan melayani responden dengan baik, berinteraksi dengan ramah serta selalu sigap ketika responden membutuhkan bantuan petugas kesehatan. Penelitian ini mendukung pendapat Larrabee (2004) dalam Senarath, et al. (2013): 11) menyatakan bahwa, interaksi dengan pasien dianggap sebagai penentu utama kepuasan pasien. Hal ini mendukung hasil penelitian Anwar (2014) menyatakan bahwa, distribusi responden berdasarkan kinerja petugas menunjukkan bahwa kinerja petugas berhubungan nyata terhadap kepuasan pasien dalam pelayanan petugas di rumah sakit Syech Yusuf Kabupaten Gowa.

Sedangkan dalam hal kepatuhan ketepatan jadwal makan ini dapat dipengaruhi oleh beberapa faktor, pada responden rawat jalan berkaitan dengan aktivitas yang dilakukan responden sehari- hari. Sehingga sulit untuk mengikuti sesuai dengan jadwal yang sudah ditentukan yaitu setiap 3 jam sekali. Sedangkan untuk responden rawat inap berkaitan dengan pemberian makanan sesuai kelas perawatan yang responden terima.

Pemberian makanan responden diabetes mellitus di kelas II dan III diberikan terakhir pada waktu sore hari. Makanan yang diberikan oleh petugas biasanya langsung dimakan oleh responden atau oleh sebagian responden malah membiarkan makanan hingga menjadi dingin karena terkait hilangnya nafsu makan. Ketidakpatuhan jadwal makan bisa juga terjadi karena adanya penambahan makanan dari luar rumah sakit yang keluarga responden bawa terkait rasa lapar yang sering dirasakan penderita diabetes mellitus. Sehingga dapat membuat responden sulit mengikuti interval jadwal makan yang benar. Hal ini mendukung pendapat Husnah (2014: 63) menyatakan bahwa, penyebab ketidakpatuhan pasien diabetes dalam menjalani diet adalah tidak 
memahami tentang manfaat diet yang baik tentang kapan dan bagaimana melaksanakan suatu terapi diet itu sendiri.

\section{Evaluasi kepuasan pasien terhadap jenis makanan diabetes mellitus di RSU PKU Muhammadiyah Bantul Yogyakarta}

Kepatuhan jenis makanan diet diabetes juga harus dikontrol karena merupakan salah satu prinsip diet diabetes yang harus responden terapkan.

Hasil penelitian di RSU PKU Muhammadiyah Bantul ini juga menunjukkan,bahwa kepatuhan jenis makanan diabetes mellitus secara parsial tidak mempunyai pengaruh yang signifikan terhadap kepuasaan pasien. Hal ini terbukti dari nilai $t_{\text {hitung }}(-0.796)$ lebih kecil dari $t_{\text {tabel }}$ $(1,987)$. Sejalan dengan hasil penelitian Anwar (2014) menyatakan bahwa, distribusi responden berdasarkan kinerja petugas menunjukkan bahwa kinerja petugas berhubungan nyata terhadap kepuasan pasien dalam pelayanan petugas di rumah sakit Syech Yusuf Kabupaten Gowa.

Sedangkan dalam hal ketidakpatuhan jenis makanan diet diabetes mellitus ini bisa dipengaruhi dari keterbatasan pengetahuan responden akibat minimnya informasi yang responden dapat. Dalam penelitian ini mayoritas responden adalah lansia yang diketahui mempunyai keterbatasan pendidikan serta masih rendahnya motivasi responden. Pengaruh dari kebiasaan pola makan responden yang belum benar sehingga terbiasa mengkonsumsi makanan yang manis.

Dalam hal ini pengetahuan responden tentang penyakit diabetes mellitus sangatlah penting karena pengetahuan ini akan membawa penderita diabetes mellitus untuk menentukan sikap, berpikir dan berusaha untuk tidak terkena penyakit atau dapat mengurangi kondisi penyakitnya. Sejalan dengan pendapatEffendi (2010) dalam Herlena (2013:69) menyatakan bahwa, semakin baik pengetahuan penderita diabetes mellitus maka semakin baik juga kepatuhan sikap penderita diabetes terhadap diet diabetes itu sendiri.

Hal ini sejalan dengan pendapat Siregar (2006) dalam Herlena (2013:70), ketidakpatuhan pasien terhadap diet dipengaruhi motivasi yang kurang dari pasien. Pasien merasa malas dan bosan dengan menu diabetes mellitus yang sesuai aturan. Hal ini mendukung pendapat dari Smet (1994) dalam farida (2015:65) menyatakan bahwa, salah satu strategi untuk meningkatkan kepatuhan adalah pemberian informasi, pemberian informasi yang jelas pada pasien dan keluarga mengenai penyakit yang dideritanya serta cara pengobatan.

\section{Penutup}

Berdasarkan hasil penelitian yang telah dilakukan dan uraian pada bab sebelumnya, maka penulis dapat mengambil kesimpulan sebagai berikut:

1. Ada pengaruh kinerja tenaga kesehatan terhadap kepuasan pasien diabetes mellitus di ruang rawat inap dan rawat jalan RSU PKU Muhammadiyah Bantul Yogyakarta.

2. Tidak ada pengaruh kepatuhan ketepatan jadwal makan terhadap kepuasaan pasien diabetes mellitus di ruang rawat inap dan rawat jalan RSU PKU Muhammadiyah Bantul Yogyakarta.

3. Tidak ada pengaruh kepatuhan jenis makanan terhadap kepuasan pasien diabetes mellitus di ruang rawat inap dan rawat jalan RSU PKU Muhammadiyah Bantul Yogyakarta

Penelitian ini tidak terlepas dari beberapa keterbatasan, berikut ini akan penulis paparkan beberapa keterbatasan tersebut antara lain

1 Dalam penelitian ini hanya memfokuskan pada variabel kinerja tenaga kesehatan, kepatuhan jadwal makan dan jenis makanan diet diabetes mellitus serta variabel kepuasaan subyek penelitian, akan lebih baik apabila ditambahkan variabel lain 
seperti kepatuhan jumlah makanan diet diabetes, sikap penderita, pengetahuan diet diabetes dan sebagainya.

2. Teknik pengumpulan data hanya diperoleh dari kuesioner, sehingga kesimpulan yang diperoleh hanya berdasarkan kuesioner tanpa adanya observasi dan wawancara lebih mendalam dengan subyek penelitian, sehingga hasil penelitian yang diperoleh kurang mendalam.

Berdasarkan hasil penelitian maka perlu disampaikan beberapa saran sebagai berikut:

1. Bagi RSU PKU Muhammadiyah Bantul Yogyakarta dalam hal kepuasan subyek penelitian diketahui tidak mempunyai pengaruh terhadap kepatuhan ketepatan jadwal makan dan jenis makanan diet diabetes mellitus. Diharapkan tenaga kesehatan dapat meningkatkan konsultasi gizi dan memberikan informasi yang lebih mendalam kepada subyek penelitian dan keluarga untuk memahami pentingnya menjalankan terapi diet diabetes mellitus dengan baik dan benar sesuai prinsip $3 \mathrm{~J}$.

2. Bagi peneliti mendatang hendaknya menambah variabel bebas lainnya. Misalnya keptuhan jumlah makanan diet diabetes, sikap penderita, pengetahuan diet diabetes mellitus dan sebagainya. Selain itu perlu menambahkan metode wawancara dan observasi secara langsung kepada responden untuk melengkapi hasil penelitian sehingga lebih komprehensif.

\section{Daftar Pustaka}

Almatsier, Sunita. (2007). Penuntun Diet. Jakarta: PT Gramedia Utama.

Azis, M. dkk. (2012). Hubungan Tenaga Medik, Rumah Sakit, Dan Pasien. Jakarta: Badan Pembinaan Hukum dan Hak Asasi Manusia RI.

Departemen Kesehatan RI. (2005). Pedoman Pelayanan Gizi Rumah Sakit. Jakarta.

Direktorat Bina Pelayanan Medik Dasar Direktorat Jendral Bina Pelayanan Medik. (2007). Pedoman Penyelenggaraan Makanan Rumah Sakit. Jakarta: DEPKES RI.

Farida. Thinni. (2015). Kepatuhan Pasien Rawat Inap Diet Diabetes Mellitus Berdasarkan Kepatuhan NIVEN. Jurnal Administrasi Kesehatan Indonesia. RSUD dr. Mohamad Soewandhie Surabaya.

Ghosh. (2014). Measuring patient satisfaction An empirical study in India. Leadership in Health Services. Vol (27): No. 3.

Ghozali, Imam. (2013). Aplikasi Analisis Multivariate Dengan Program. Semarang: Badan Penerbit Universitas Diponegoro.

Hafid, Anwar. (2014). Hubungan Kinerja Perawat Terhadap Tingkat Kepuasan Pasien Pengguna YANKESTIS Dalam Pelayanan Keperawatan. Jurnal Kesehatan, RSUD Syech Yusuf Kab. Gowa.

Hawthorne. et al. (2014). Measuring Patient Satisfaction with Health Care Treatment Using The Short Assesment Of Patient Satisfaction Measure Delivered Superior and Robust Satisfaction Estimates. Journal of Clinical Epidemiology.

Herlambang Susatyo. (2016). Manajemen Pelayanan Kesehatan Rumah Sakit. Yogyakarta: Gosyen Publishing. 
Herlena. Widiyaningsih. (2013). Hubungan Antara Pengetahuan Dan Sikap Penderita Diabetes Mellitus Dengan Kepatuhan Diet Diabetes Mellitus. Timur. Jurnal Keperawatan Medikal Bedah. RSUD AM Parikesit Kalimantan

Husna dkk. (2014). Hubungan Pengetahuan Dengan Kepatuhan Pasien Diabetes Mellitus Dalam Menjalani Terapi. Jurnal Kedokteran Syiah Kuala. RSUD Dr. Zainoel Abidin Banda Aceh.

Insiyah. Rini. (2015). Tingkat Kepatuhan Dan Pengetahuan Tentang Diet Diabetes Mellitus Pada Pasien Diabetes Mellitus Di Puskesmas Sibela Kota Surakarta. Jurnal Terpadu Ilmu Kesehatan.

Kotler \& Keller. (2007). Manajemen Pemasaran. Jakarta: INDEKS.

Mangkunegara, Anwar P. (2000). Kinerja. Http://id.wikipedia.org/wiki/URL. Diakses pada tanggal 29 Desember 2016.

Messina. et al. (2012). Patients' evaluation of hospital foodservice quality in Italy: what do patients really value. Public Health Nutrition.

Notoatmodjo, Soekidjo. (2002). Metodologi Penelitian Kesehatan. Jakarta: Rhineka Cipta.

Notoatmodjo, Soekidjo. (2010). Metodologi Penelitian Kesehatan. Jakarta: Rhineka Cipta.

Notoatmodjo. Soekidjo. (2010). Etika dan Hukum Kesehatan. Jakarta: Rhineka Cipta

Perkeni. (2011). Konsensus Pengelolaan dan Pencegahan Diabetes Mellitus tipe 2 di Indonesia. Jakarta.

Pohan, Imbalo S. (2013). Jaminan Mutu Layanan Kesehatan. Jakarta: EGC.

Prayugo. Dkk. (2012). Pola Diet Tepat Jumlah, Jadwal, dan Jenis Terhadap Kadar Gula Darah Pasien Diabetes Mellitus Tipe II. Jurnal STIKES, Rumah Sakit Baptis Kediri.

Risnasari, Norma. (2014). Hubungan Tingkat Kepatuhan Diet Pasien Diabetes Mellitus Dengan Munculnya Komplikasi. Jurnal Universitas Nusantara PGRI Kediri.

Senarath, et al. (2013). Patient satisfaction with nursing care and related hospital services at the National Hospital of Sri Lanka. Leadership in Health Services. Vol (26): No. 1.

Semedi, Pujo. Dkk. (2013). Hubungan kepuasan pelayanan makanan rumah sakit dan asupan makanan dengan perubahan status gizi pasien. Jurnal Gizi Indonesia, RSUD Sunan Kalijaga Kabupaten Demak.

Siregar, Syofian. (2010). Statistika Deskriptif Untuk Penelitian. Jakarta: PT. Raja Grafindo Persada.

Sujarweni, Wiratna. (2014). Metodologi Penelitian. Yogyakarta: Pustaka baru press.

Tsudian, (2011). Hubungan Kepuasan Pasien Terhadap Mutu Pelayanan Kesehatan. Jurnal Kesehatan Masyarakat, Rumah Sakit Cut Mutia Kabupaten Aceh Utara.

Supriyanto. (2010). Konsep Kepatuhan. http://dr-suparyanto.blogspot.co.id/2010/10/konsepkepatuhan-1.html. Diakses pada tanggal 27 Januari 2017

Yousapronpaiboon, Khanchitpol. (2003). Measuring hospital out-patient service quality in Thailand. Jurnal Leadership in Health Services. Vol (26): No. 4. 